This item was submitted to Loughborough's Research Repository by the author.

Items in Figshare are protected by copyright, with all rights reserved, unless otherwise indicated.

\title{
Steady-state assessments of PMSGs in wind generating units
}

PLEASE CITE THE PUBLISHED VERSION

http://dx.doi.org/10.1016/j.ijepes.2017.02.002

\section{PUBLISHER}

(C) Elsevier

\section{VERSION}

AM (Accepted Manuscript)

\section{PUBLISHER STATEMENT}

This work is made available according to the conditions of the Creative Commons Attribution-NonCommercialNoDerivatives 4.0 International (CC BY-NC-ND 4.0) licence. Full details of this licence are available at: https://creativecommons.org/licenses/by-nc-nd/4.0/

\section{LICENCE}

CC BY-NC-ND 4.0

\section{REPOSITORY RECORD}

Bonfiglio, Andrea, Federico Delfino, Francisco M. Gonzalez-Longatt, and Renato Procopio. 2019. "Steadystate Assessments of Pmsgs in Wind Generating Units". figshare. https://hdl.handle.net/2134/23598. 


\title{
Steady-State Assessments of PMSGs in Wind Generating Units
}

\author{
A. Bonfiglio ${ }^{1}$, F. Delfino ${ }^{1}$, F. Gonzalez-Longatt ${ }^{2}$, and R. Procopio ${ }^{1}$ \\ ${ }^{1}$ University of Genoa, Department of Naval, Electrical, and ICT Engineering \\ Via Opera Pia 11a, I-16145 Genova, ITALY \\ ${ }^{2}$ Loughborough University, School of Electronic, Electrical and Systems Engineering \\ Loughborough, UNITED KINGDOM.
}

Corresponding author: Dr. Andrea Bonfiglio

Department of Naval, ICT and Electrical Engineering

University of Genoa,

Via Opera Pia 11a, I-16145 Genova, ITALY.

Tel. +390103532730

e-mail: a.bonfiglio@unige.it. 


\begin{abstract}
The number of fully-rated converter wind turbine generators equipped with a Permanent Magnet Synchronous Generator (PMSG) has sensibly increased in the late years. The optimal utilization and controllability of a PMSG is achieved using a Pulse Width Modulation - Voltage Source Converter (PWM-VSC) that allows interfacing the electric machine with the distribution network by means of a DC link. The generator/Machine-Side Converter (MSC) controls the operation of the PMSG. This paper proposes a methodology to assess the feasibility of the steady-state working points of PMSG based wind turbines without running a set of time-consuming time-domain simulations. Three control objectives for MSC are usually considered: stator voltage control, unitary power factor control and torque control. The aim of the present paper is that of providing an analytical methodology to check the feasibility of the steady-state working points dictated by different control strategies of the MSC starting from the specific operational constraints provided by the wind power plants characteristics. The effectiveness of the proposed methodology is demonstrated comparing numerical results of a $\mathrm{MATLAB}^{\circledR}$ implementation against dedicated time-domain simulations. Simulations results demonstrated the appropriate performance of the proposed methodology characterized by the almost negligible computational time required.
\end{abstract}

Index terms: Capability chart, electric machines, power system modeling and wind power generation.

\title{
1. Introduction
}

The technology used in wind energy is evolving towards larger generation units (longer rotor blades, taller towers and more powerful generators) [1]. Many modern utility-scale Wind Turbine Generators (WTG) use fully-variable speed and pitch-regulated control systems in order to optimize the energy captured at low-wind speeds and reducing the stress on mechanical components [2]. The use of partial or fully-rated power converter, between the electric generator and the power grid, has increased in recent times because of the augmented requirements on grid integration [3]. The mostly 
used generators in variable speed wind energy conversion are Doubly Fed Induction Generators (DFIGs), and Synchronous Generators (SG) [4].

Permanent Magnet Synchronous Generator (PMSG) are more efficient than the traditional DFIG and electrically excited synchronous generators, especially operating at partial load [5]. Additionally, permanent magnet generators have fewer moving parts with respect to electrically excited ones and wound rotor induction generators, being more robust and requiring less maintenance [1], [4].

The use of PMSG, combined with Fully-Rated Power Converter (FRPC) is becoming a popular option for a variable-speed generation mainly because of a longer lifetime [6], higher overall efficiency [3], despite their relatively high initial costs [1, 7].

The PMSG operation in the context of wind power production is very different from the traditional SG directly connected to the power grid. SG used for a traditional grid-scale generation has at least two local controllers [8]: (i) prime-mover control which controls either the speed or the output power of the generator unit according to a preset power-frequency characteristic and (ii) excitation control or automatic voltage regulator (AVR) which acts on the excitation current, and consequently controls the generator terminal voltage [9].

The PMSG used for wind power applications requires controllers in order to extract the maximum amount of power from the wind source and to be compliant with the grid integration requirements. The PMSG is connected to the grid through a frequency converter (see Fig 1) [10]. The generator/Machine-Side Converter (MSC) can be a diode-based rectifier or a PWM voltage source converter, the Grid-Side Converter (GSC) is normally a PWM Voltage Source Converter (VSC) [10]. However, the optimal utilization and controllability of a PMSG can be achieved if a PWMVSC is used at the generator side [11]. The back-to-back converters can be controlled independently through the decoupled $d-q$ frame control [12]. The MSC controls the operation of the PMSG and the GSC controls the DC link voltage by exporting active power to the network [10]. 


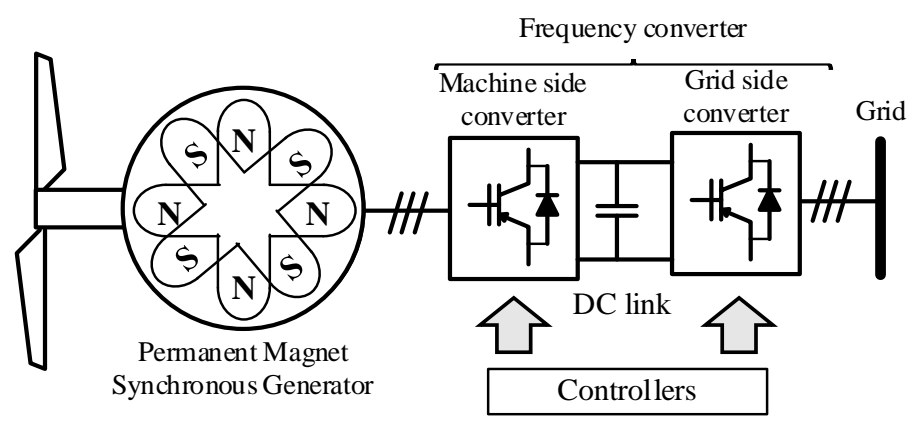

Fig. 1: Typical configuration of a direct-drive PMSG wind turbine considering back-to-back chain using PWM-VSC.

The strategy to control the operation of the PMSG is based in a multi-layer controller at the MSC:

(i) The fast-acting inner controller is used to control the stator currents $\left(I_{S}\right)$ in a rotating $d$ - $q$ frame;

(ii) the outer-slower controllers are used for torque $\left(T_{e}\right)$ and/or reactive power control $\left(Q_{g r i d}\right)$.

Three main control objectives for the MSC are highlighted in literature [13], [11]: stator voltage control, unitary power factor control and torque control.

The torque control strategy for the MSC must be very fast and precise. The literature reports three possible objectives: ensure maximum power point tracking (MPPT) [11] of the wind turbine, nominal torque generation for wind speeds above the nominal speed and maximum torque [14] where the generator provides the maximum possible torque. Controlling the torque generation provides several advantages: high-efficiency operation, reducing the stresses on the mechanical components, reduces the torque ripples in the generator shaft and reduces the total harmonic distortion. However, this controller acts on the q-axis only, as a consequence the reactive power production is no controlled and the MSC or generator may be overloaded.

The unity power factor controller controls the $\mathrm{d}-\mathrm{q}$ axis current at the PMSG stator, it allows the reactive power production compensation [13]. As the PMSG operates at unitary power factor, this operational regime minimizes the converting rating but do not provide a direct control of the stator voltage, in fact, the voltage varies with the rotor speed, as a consequence the main disadvantage of this control is the risk of overvoltage in the case of an over speed [11], [15]. 
The stator voltage control strategy aims at keeping a constant ration between the machine voltage and speed (if possible). For this reason, this control strategy needs to reduce the machine voltage in accordance to the speed and limit it in case of speed condition above the rated speed [16]. However, a disadvantage of this controller is the reactive power demand of the generator may result in an overload of the MSC.

The main control objectives for MSC reported in the literature show several drawbacks that need to be taken into account in order to guarantee a stable operation of the PMSG in wind power applications. No matter the effectiveness of the control system used, a preliminary steady-state analysis is needed in order to check whether the control objective can be reached, that is to say, to verify if the desired equilibrium point exists or the desired trajectory can be tracked. Therefore, the objective of this paper is to propose a methodology to assess the feasibility of the steady-state working points of the PMSG based WTG without the necessity to perform a set of time-domain simulations. The proposed methodology is based on an analytical approach where the steady-state assessment of the control strategies feasibility is obtained with almost zero computational effort. The critical steady-state operational limits are found using a very compact mathematical process based on the PMSG electrical parameters.

The proposed methodology is a simple way to evaluate the limits of the steady-state operation of the PMSG based fully-rated converter wind turbine in accordance to the implemented control strategy. The permanent magnet flux is found to be a critical parameter on feasible steady state operational points, as a consequence, the proposed methodology may be attractive to the wind turbine industry because it will allow an appropriate selection of the control strategy based on the permanent magnet characteristics. Moreover, it can be useful to properly evaluate the value of the permanent magnet flux to exploit at best the capabilities of the magnet. This is an important aspect at the light of the fact that the high price of PMSG is mainly related to the cost of magnet row material (mostly neodymium and dysprosium). 


\section{List of symbols}

In this section, a list of all the variables and symbols involved in the problem formulation is presented.

- $\mathrm{j}$ is the imaginary unit

- $\omega_{r}$ is the wind generator rotor angular speed;

- $\omega_{r}^{*}$ is the wind generator rotor angular speed reference;

- $\quad P_{W T}$ is the wind power;

- $\quad P_{W T} *$ is wind power maximum power according to the MPPT curve;

- $P_{\max }$ is maximum wind power;

- $\quad v_{w}$ is the wind speed;

- $\quad v_{m d(q)}$ is the direct (quadrature) axis component of the machine voltage;

- $R_{S}$ is the stator resistance;

- $i_{s d(q)}$ is the direct (quadrature) axis component of the current outgoing from the machine;

- $\quad \phi_{\operatorname{md}(q)}$ is the direct (quadrature) axis component of the machine linkage;

- $x_{d}$ is the stator direct axis reactances at rated frequency;

- $\quad x_{q}$ is the stator quadrature axis reactances at rated frequency;

- $\quad \psi$ is the permanent magnet flux;

- $v_{s d(q)}$ is the direct (quadrature) axis component of the voltage at the machine side converter terminals;

- $R$ is the resistance of the cable connecting the machine to the machine side converter;

- $\quad L$ is the inductance of the cable connecting the machine to the machine side converter;

- $V_{m}$ is the module of the machine voltage;

- $V_{m} *$ is the reference of the machine voltage module;

- $V_{m, \max }$ is the maximum value of the machine voltage module;

- $Q$ is the machine reactive power; 


\section{Formulation of the problem}

\subsection{Steady-state characterization of the WTG}

Fig 1 shows a direct-drive WTG based on PMSG with full-rated converter enabling the variable speed operation of the PMSG (main electro-mechanical variables and conventions are depicted). The MSC controls the power extracted from the wind turbine $\left(P_{W T}\right)$, performing the so-called MPPT, and the voltage at the machine terminals $\left(V_{m}\right)$, while the GSC is usually responsible for maintaining constant the DC link voltage $\left(V_{d c}\right)$ and for the reactive power provision to the grid $\left(Q_{\text {grid }}\right)[10]$. Therefore, the first noteworthy differences with respect to a traditional SG are that the aim of the power regulation is to follow the availability of the primary source rather than minimizing the overall energy cost and that both active power and voltage are controlled adjusting the MSC parameters. The aim of this section is to provide a mathematical model of the wind turbine system which allows verifying if a steady-state working point characterized by a specific value of the wind power and of the machine voltage can be reached acting on the MSC.

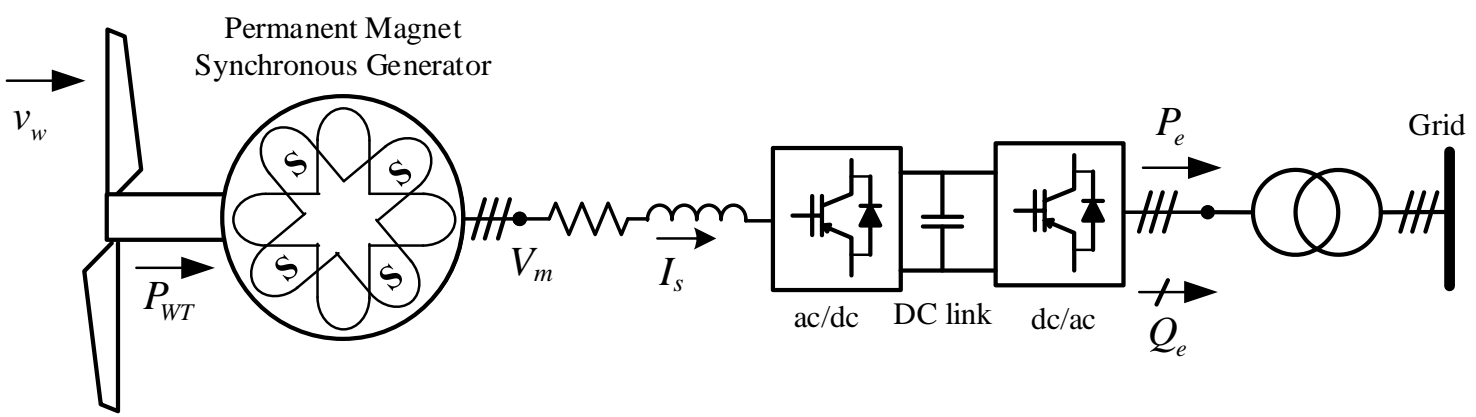

Fig. 2: General structure of a variable-speed WT with a direct-drive PMSG with FRPC [2].

As well known, for any wind speed $\left(v_{w}\right)$, there exists only one turbine angular speed $\omega_{r}^{*}$ that allows extracting the maximum power $P_{W T} *$ from the wind $[17,18]$. As a consequence, to maximize its power production, the following power-rotor speed control curve (MPPT curve) can be defined [19], [20]:

$$
P_{W T}^{*}\left(\omega_{r}\right)=\left\{\begin{array}{cl}
0, & \omega_{r}<\omega_{\min } \\
g\left(\omega_{r}^{*}\right), & \omega_{\min } \leq \omega_{r}<\omega_{\max } \\
P_{\max }, & \omega_{r} \geq \omega_{\max }
\end{array}\right.
$$


where the function $g\left(\omega_{r}\right)$ maps the locus of the maximum values of the function $P_{W T}$ defined in correspondence of the possible values of the wind speed $\left(v_{w}\right)$ with pitch angle $(\theta)$ equal to zero, providing the following relation:

$$
g\left(\omega_{r}\right)=\max _{\omega_{r}}\left\{P_{W T}\left(\omega_{r}, v_{w}, \theta=0\right)\right\}
$$

This implies that, for any fixed wind speed, the machine angular speed, and the power extracted from the primary source result uniquely determined by (1) and (2).

The steady-state electrical equations of the stator of a PMSG in the $d$-q reference frame, with the passive sign convention from a mechanic point of view and the active sign convention from the electric point of view, (in pu on the generator basis) are given by [5]:

$$
\left\{\begin{array}{l}
v_{m d}=-R_{s} i_{s d}-\omega_{r} \phi_{s q} \\
v_{m q}=-R_{s} i_{s q}+\omega_{r} \phi_{s d}
\end{array}\right.
$$

where $R_{s}$ is the stator resistance, $v_{m d(q)}$ is the direct (quadrature) axis component of the machine voltage, $i_{s d(q)}$ is the direct (quadrature) axis component of the current outgoing from the machine (see Fig. 2) and $\phi_{m d(q)}$ is the direct (quadrature) axis component of the machine linkage. The magnetic stator equations are the following:

$$
\left\{\begin{array}{l}
\phi_{s d}=x_{d} i_{s d}+\psi \\
\phi_{s q}=x_{q} i_{s q}
\end{array}\right.
$$

where $x_{d}, x_{q}$ and $\psi$ are the stator direct and quadrature axis reactances at rated frequency and the permanent magnet flux respectively. Finally, the electromagnetic torque $\left(T_{e}\right)$ is given by:

$$
T_{e}=-i_{s d} \phi_{s q}+i_{s q} \phi_{s d}=\left(x_{d}-x_{q}\right) i_{s d} i_{s q}+\psi i_{s q}
$$

The MSC can be considered as a voltage source (Vs), which axis components $v_{s d}$ and $v_{s q}$ can be adjusted acting on the PWM inverter parameters. Such voltage is related to the PMSG one according to the following relationships:

$$
\left\{\begin{array}{l}
v_{s d}=v_{m d}-R i_{s d}-\omega L i_{s q} \\
v_{s q}=v_{m q}-R i_{s q}+\omega L i_{s d}
\end{array}\right.
$$

Where $R$ and $L$ are the connection cable resistance and inductance respectivelly. The steady-state active power balance on the PMSG allows stating that: 


$$
P^{*}{ }_{W T}-R_{s}\left(i_{s d}{ }^{2}+i_{s q}{ }^{2}\right)=v_{m d} i_{s d}+v_{m q} i_{s q}
$$

Now, inserting (4) into (3), and (3) into (7) one has:

$$
P^{*}{ }_{W T}=\omega_{r}^{*}\left(x_{d}-x_{q}\right) i_{s d} i_{s q}+\omega_{r}^{*} \psi i_{s q}
$$

As a consequence, for a given couple $\left(\omega_{r}{ }^{*}, P_{W T^{*}}\right)$, the equation (8) expresses the mathematical relation between the current axis components in order to track the maximum power point (MPP). The second degree of freedom provided by the MSC can be used to pursue another specific control objective. According to [13] three main control strategy can be highlighted: (i) the constant $V_{m} / f$ $(V f)$ regulation mode, (ii) the Unitary Power Factor $(U P F)$ control and (iii) the Maximum Torque (MT) control.

\subsection{Constant V/f regulation (Vf) strategy}

In the constant $V / f$ regulation mode, the PMSG stator voltage amplitude $V_{m}$ is set according to the desired generator speed $\left(\omega_{r}^{*}\right)$. In other words, the per unit stator voltage amplitude is equal to the per unit values of the generator rotor speed until its maximum value, that is to say:

$$
V_{m}^{*}=\min \left\{\omega_{r}^{*}, V_{m, \max }\right\}
$$

where $V_{m, \max }$ represents the maximum allowed stator voltage (e.g. $1.00 \mathrm{pu}$ ) and $V_{m}^{*}$ the stator desired voltage amplitude, this valued can bebtained by inserting (4) into (3), i.e.:

$$
V_{m}^{*}=\sqrt{\left(R_{s} i_{s d}+\omega_{r}^{*} x_{q} i_{s q}\right)^{2}+\left(\omega_{r}^{*}\left(x_{d} i_{s d}+\psi\right)-R_{s} i_{s q}\right)^{2}}
$$

\subsection{Unitary Power Factor (UPF) control}

In the UPF control strategy, the stator current $\left(I_{S}=i_{s d}+j i_{s q}\right)$ is controlled to fully compensate reactive power at the generator stator [13]. However, as the stator voltage is not directly controlled, over/under voltage issues may arise. In accordance with (3), the PMSG reactive power constraint can be expressed as:

$$
Q=v_{m d} i_{s q}-v_{m q} i_{s d}=-\left(R_{s} i_{s d}+\omega x_{q} i_{s q}\right) i_{s q}-\left(\omega x_{d} i_{s d}+\omega \psi-R_{s} i_{s q}\right) i_{s d}=0
$$

\subsection{Maximum Torque (MT) control}


In the MT control, the stator current $\left(I_{S}\right)$ is controlled to have $q$-axis component only [13]. The main idea supporting this strategy is to exploit the fact that, neglecting the PMSG rotor saliency, the torque $\left(T_{e}\right)$ only depends on the $q$-axis current -see (5). As a consequence, choosing the reference signal for the $d$-axis current equal to zero allows obtaining the torque necessary to follow the MPPT curve with the minimum current amplitude. Nevertheless, as for the UPF strategy, no control action can be done on the voltage that can, therefore, lay outside the admissible range. Here is proposed a modification of such strategy in order to pose suitable constraints on the voltage amplitude. As the aim of this regulation strategy is to minimize the stator current amplitude while following the MPPT curve, it is possible to set up the following optimization problem:

find the minimum of:

$$
F\left(i_{s d}, i_{s q}\right)=i_{s d}{ }^{2}+i_{s q}^{2}
$$

subject to the active power balance and the machine voltage constraints:

$$
\left\{\begin{array}{c}
P^{*}{ }_{W T}=\omega_{r}^{*}\left(x_{d}-x_{q}\right) i_{s d} i_{s q}+\omega_{r}^{*} \psi i_{s q} \\
\sqrt{\left(R_{s} i_{s d}+\omega_{r}^{*} x_{q} i_{s q}\right)^{2}+\left(\omega_{r}^{*}\left(x_{d} i_{s d}+\psi\right)-R_{s} i_{s q}\right)^{2}} \leq V_{m, \max }
\end{array}\right.
$$

\subsection{Steady-state assessment of the control strategies feasibility}

The question which arises at this point is whether the steady-state operational points dictated by the three different control strategies can be reached for any value of the wind speed in the WTG operating range, by acting on the MSC parameters. To answer this question, one has to find the solution (if possible) of the mathematical equations describing the steady-state operation of the control strategy equations: (8)-(10) for the Vf strategy, (8)-(11) for the UPF strategy, and the optimization problem (12)-(13) for the MT one. It must be noticed that if a solution of the mathematical problem exists, then the voltage axis components $v_{s d}$ and $v_{s q}$ at the AC side of the MSC can be always found inserting (4) into (3) and (3) into (6). Moreover, even if the desired steady-state working point exists, it should not cause overload on the MSC or the PMSG. This condition can be checked verifying that: 


$$
\left|I_{S}\right|=\sqrt{i_{s d}{ }^{2}+i_{s q}^{2}} \leq I_{s, \max }=1.00 p u
$$

\subsection{Physical insight into the feasibility conditions}

Unfortunately, none of the three steady-state operation of the control strategy problems can be solved analytically, (8)-(10) for the Vf strategy, (8)-(11) for the UPF strategy, and the optimization problem (12)-(13) for the MT strategy. This makes it impossible to get some physical insight on the conditions under which the desired steady-state working point is feasible. To overcome this problem, the following simplified analysis is proposed.

Suppose to neglect the stator resistance and the rotor saliency; i.e. imposing $R_{s}=0$ p.u. and $x_{d}=x_{q}=x$. Under these assumptions, (8) becomes:

$$
i_{s q}=\frac{P_{W T}^{*}}{\omega_{r}^{*} \psi}
$$

In the case of the $V f$ strategy, (10) originates the following second-degree equation in terms of the $d$-axis component of the stator current:

$$
\left(\omega_{r}^{*} x\right)^{2} i_{s d}^{2}+2 \omega_{r}^{* 2} x \psi i_{s d}+\omega_{r}^{* 2} \psi^{2}-V_{m}^{* 2}+x^{2} \frac{P_{W T}^{* 2}}{\psi^{2}}=0
$$

that admits, at least, one real solution if the following condition is satisfied:

$$
\psi \geq \frac{x P_{W T}^{*}}{V_{m}^{*}}
$$

Moreover, after some algebraic manipulations, one has that:

$$
I_{s}^{2}=i_{s d}^{2}+i_{s q}^{2}=\frac{\psi^{2}}{x^{2}}+\frac{V_{m}^{* 2}}{x^{2} \omega_{r}^{* 2}}-\frac{2 \sqrt{V_{m}^{* 2} \psi^{2}-x^{2} P_{W T}^{* 2}}}{x^{2} \omega_{r}^{*}}
$$

whose first derivative with respect to the permanent magnet flux $(\psi)$ is:

$$
\frac{d I_{s}^{2}}{d \psi}=\frac{2 \omega_{r}^{* 3} x^{2} \psi}{\sqrt{V_{m}^{* 2} \psi^{2}-x^{2} P_{W T}^{* 2}}}\left[\omega_{r}^{*} \sqrt{V_{m}^{* 2} \psi^{2}-x^{2} P_{W T}^{* 2}}-V_{m}^{* 2}\right]
$$

Equation (19) provides a positive value if the permanent magnet flux satisfies:

$$
\psi \geq \sqrt{\left(\frac{x P_{W T}^{*}}{V_{m}^{*}}\right)^{2}+\frac{V_{m}^{* 2}}{\omega_{r}^{* 2}}}
$$


Inequality (20) gives a limit on the minimum of (18) after which the current amplitude starts increasing indefinitely. Examining (20), it is apparent that if the permanent magnet flux becomes too high, the stator current will increase beyond the maximum allowed, thus overloading the MSC and the PMSG.

In the UPF strategy, (11) originates the following second-degree equation in terms of the $d$-axis component of the stator current:

$$
x i_{s d}^{2}+\psi i_{s d}+x \frac{P_{W T}^{*}}{\omega_{r}^{*} \psi}=0
$$

that admits, at least, one real solution if the following condition is satisfied:

$$
\psi \geq \sqrt[3]{\frac{4 x^{2} P_{W T}^{*}}{\omega_{r}^{*}}}
$$

In this case, it can be shown that the relationship between the PMSG current amplitude and the permanent magnet flux is always increasing, thus leading to the conclusion that such flux cannot exceed a certain value in order not to overload the MSC and/or PMSG.

In the $M T$ regulation mode, as $i_{s q}$ is given by (15), problem (12)-(13) corresponds to find out the minimum $d$-axis stator current that solves the second of (13) that, according to the simplifying assumptions posed in this subsection, becomes:

$$
\left(\omega_{r}^{*} x\right)^{2} i_{s d}^{2}+2 \omega_{r}^{* 2} x \psi i_{s d}+\omega_{r}^{* 2} \psi^{2}-V_{m, \max }^{2}+x^{2} \frac{P_{W T}^{* 2}}{\psi^{2}} \leq 0
$$

If $\omega_{r}^{* 2} \psi^{2}+x^{2} \frac{P_{W T}^{* 2}}{\psi^{2}} \leq V_{m, \max }^{2}$ condition $i_{s d}=0$ satisfies the inequality (23) leading to a solution of the problem (12)-(13) that is the same as the one proposed in [13] otherwise, one has to look for the minimum amplitude of $i_{s d}$ that satisfies inequality (23). Such an equation is formally equal to (16), substituting $V_{m}{ }^{*}$ with $V_{m \text {,max }}$ that leads to conditions (17) and (20).

This simplified analysis allows concluding that, for any of the three MSC control strategies, one can calculate a lower threshold for the permanent magnet flux under which the working point does exist and an upper bound that should not be exceeded not to overload the MSC and/or PMSG. 


\section{Application and validation of the proposed methodology}

In the present section, the proposed methodology is applied to a simple test case in order to demonstrate its applicability and effectiveness. Simulations results demonstrate that the proposed methodology is perfectly able to predict the steady-state operational point and check whether the working point is feasible without using time-domain simulations. To do this, a comparison between the results provided by the proposed approach and the ones obtained by time-domain simulations is presented highlighting the good agreement between the two methods and the (implementation and CPU) time saving guaranteed by the proposed algorithm.

The test system consists of variable-speed wind turbine with a direct-drive PMSG which is connected to an ideal external grid using a fully-rated power converter. The parameters used in the tests are escalated to simulate an equivalent $2 \mathrm{MW}$ wind turbine the main parameters of the PMSG are shown in Table I [21].

Table I - PMSG parameters used for the simulation purposes

\begin{tabular}{|l|c|}
\hline Rated apparent power $\left(S_{R}\right)$ & $2 \mathrm{MVA}$ \\
\hline Rated voltage $\left(V_{n}\right)$ & $690 \mathrm{~V}$ \\
\hline Stator Resistance $\left(R_{s}\right)$ & $0.042 \mathrm{pu}$ \\
\hline Direct axis reactance $\left(x_{d}\right)$ & $1.050 \mathrm{pu}$ \\
\hline Quadrature axis reactance $\left(x_{q}\right)$ & $0.75 \mathrm{pu}$ \\
\hline
\end{tabular}

Fig. 3 shoes the schematic representation of the complete control system of the WTG used for timedomain simulations (details can be found in [2, 5, 7, 20]). A full explanation of the model shown in Fig 3 is beyond the scope of this paper. For effectiveness purposes, two sets of simulations are performed in this section: (i) Simulations using the proposed methodology: the authors have implemented a Matlab/Simulink [22] program where all the model equations of the test system and the controllers (as shown in Fig 3) are solved using the proposed methodology. This program includes the three main MSC control strategies: Pf/UPF/MT; (ii) Time-domain simulations: a commercial power system analysis program, that contains suitable models of the PMSG together with the power electronics converters and of the wind turbine (see [23]), is used to perform time- 
domain simulations. All simulations are performed using a PC based on Intel ${ }^{\circledR}$, CoreTM i77410HQ CPU 2.5GHz, 16 GB RAM with Windows 8.1 64-bit operating system.

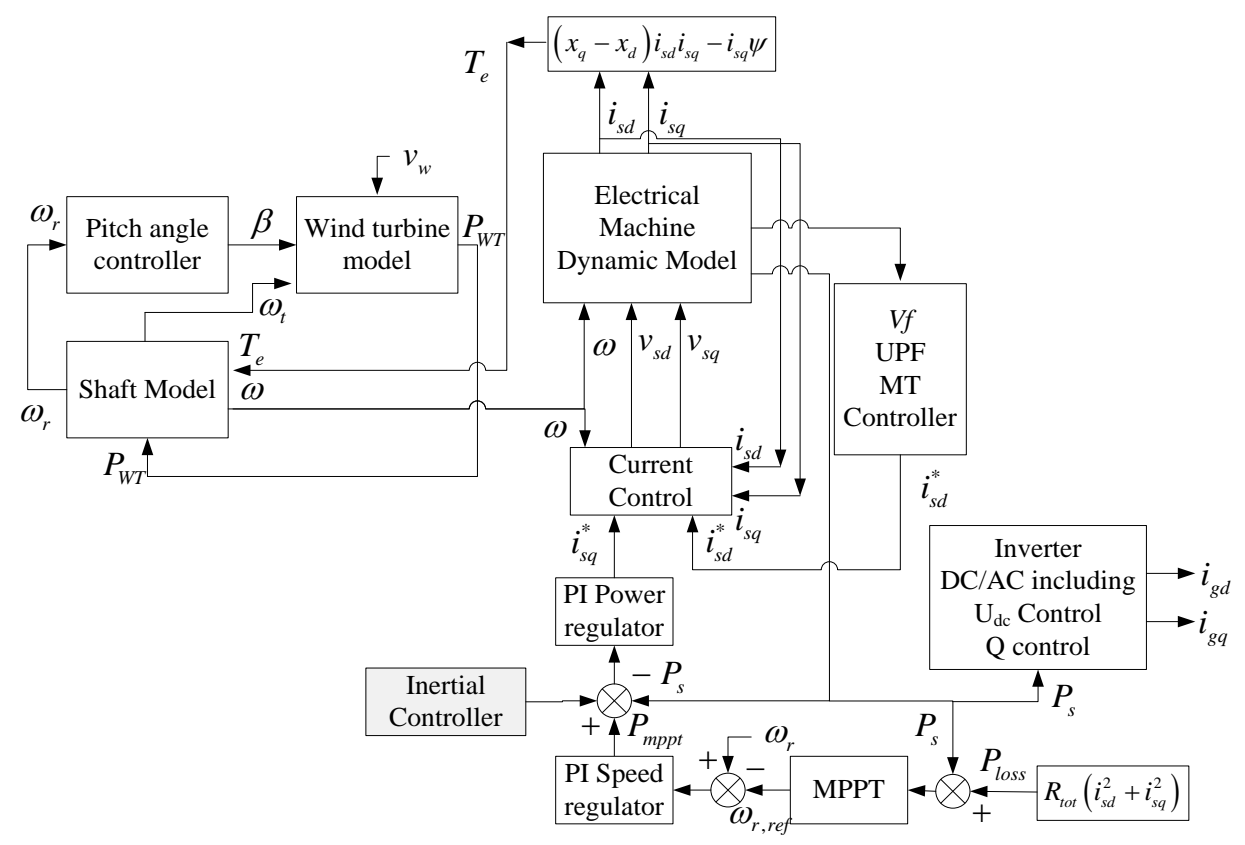

Fig. 3: Schematic block diagram representing the main components, controller and signals of WTG with PMSG.

\subsection{Constant V/f regulation (Vf) strategy}

Fig. 3 shows the relationship between the PMSG stator current and the active power delivered to the grid, obtained subtracting the machine losses from the available wind power. Three curves (corresponding to three different values of the permanent magnet flux) have been plotted considering a wind power range between $0.2 S_{R}$ and $S_{R}$. As can be seen, if the permanent magnet flux is too small, it is not possible to deliver more than $90 \%$ of the maximum wind power; otherwise, if such value is increased, it is possible to solve system (8)-(10) for all the values of wind power without overloading the machine. A further increase in the permanent magnet flux would cause the machine overload for high values of the wind power. 


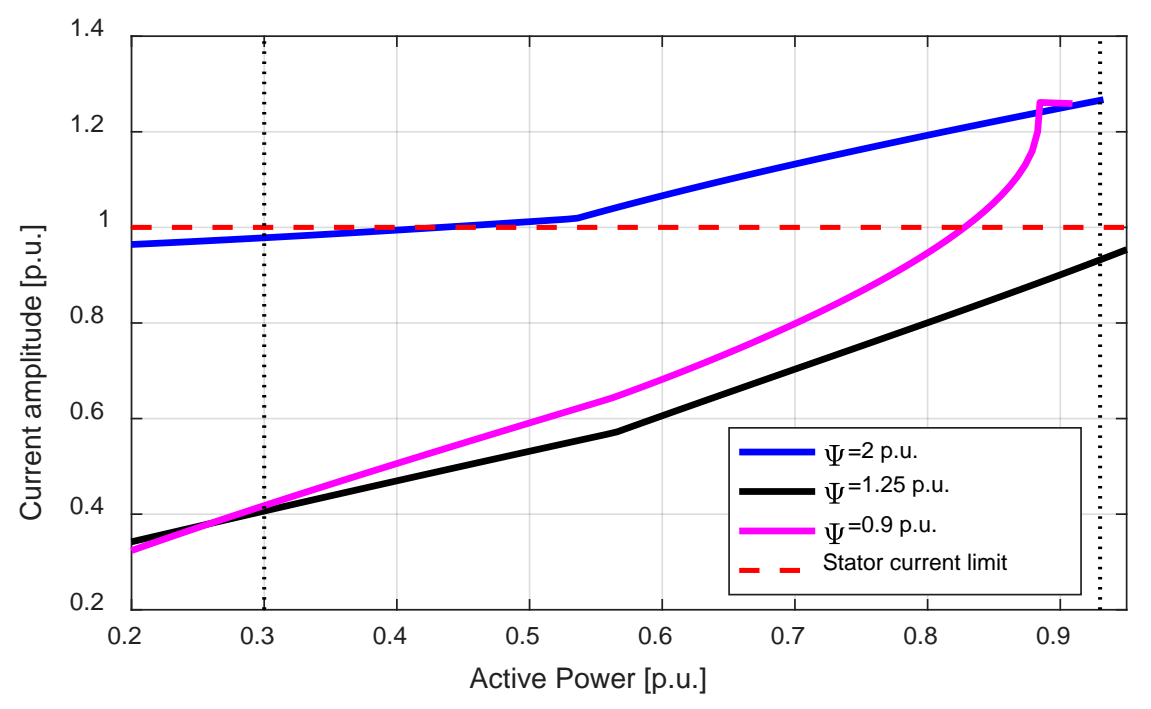

Fig. 4: Active power/current plots in the constant $V / f$ regulation mode.

In order to assess the validity of the graphs presented in Fig. 4, a time domain simulation has been set up in which the system starts from a balance point in which the active power is 0.3 pu. (corresponding to the first vertical line in Fig. 4) and is subjected to a step variation in the wind speed that causes an increase in the active power till 0.95 (corresponding to the second vertical line in Fig. 4). The intersection between the black line (permanent magnet flux equal to $1.25 \mathrm{pu}$ ) and the second vertical line in Fig. 4 states that the final point reached in this situation is characterized by a current which is approximately 0.95 pu (that does not overload the machine). This is confirmed by the black line in Fig. 5 whose final value is in excellent agreement with the one predicted by the proposed methodology. The same applies if one compares the two blue lines in Fig. 4 and Fig. 5 respectively: in both cases, the current reaches a value about 1.25 pu that overloads the PMSG and/or MSC. Finally, the exam of the two magenta curves in Fig. 4 and Fig. 5 clearly states that there is no final steady-state working point. 


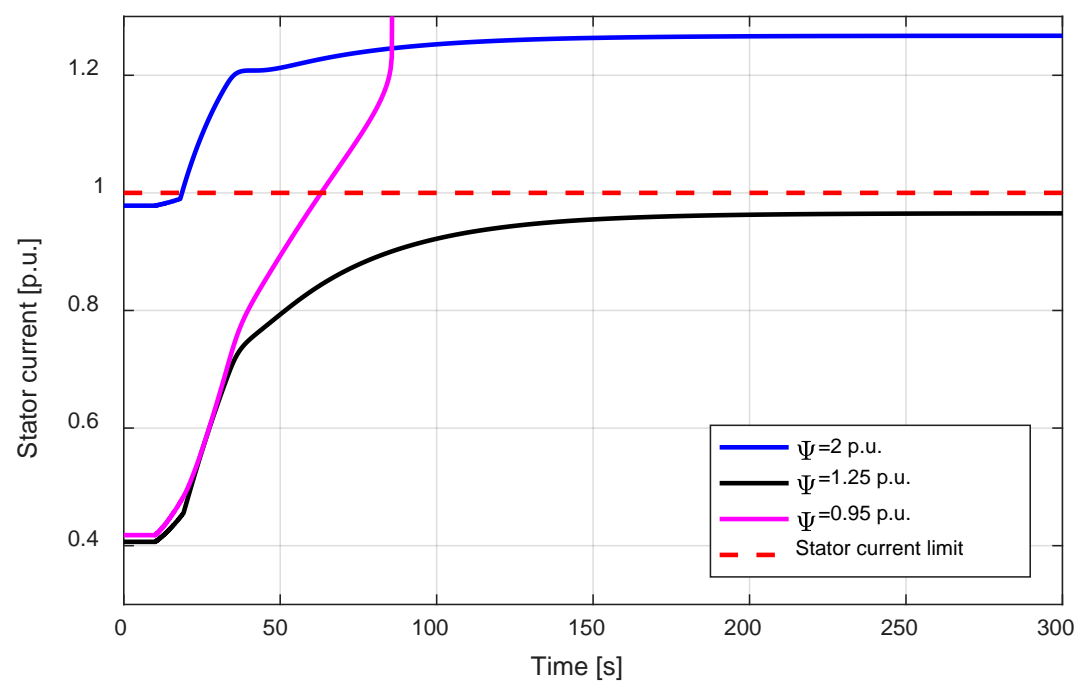

Fig. 5: Time domain simulation in the constant $V / f$ regulation mode.

\subsection{Unitary Power Factor UPF) regulation strategy}

The active power/machine current diagram and the active power/machine voltage diagram are plotted in Figs. 6 and 7 respectively for the UPF control strategy. The analysis of the graphs allows concluding that a too small value of the permanent magnet flux makes the majority of the working point unfeasible, while, increasing such value, will lead to a machine overvoltage, thus confirming the conclusions drawn in [13].

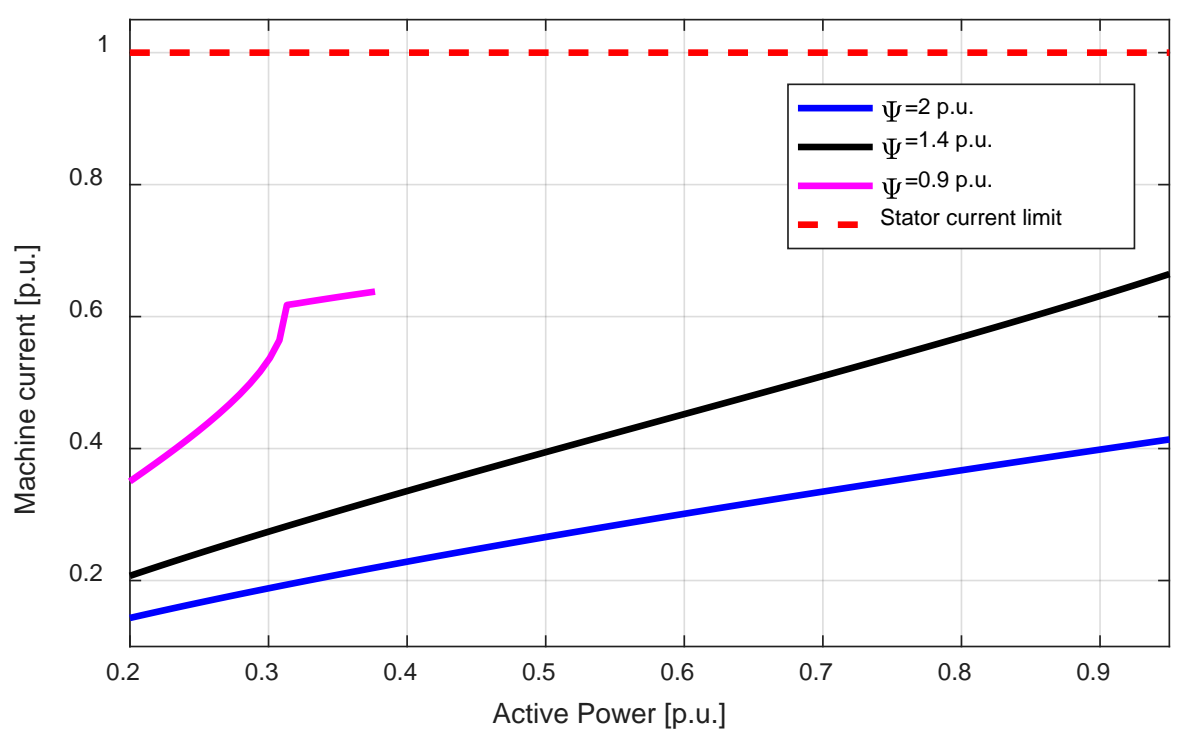

Fig. 6: Plot of active power versus PMSG terminal voltage: UPF regulation mode. 


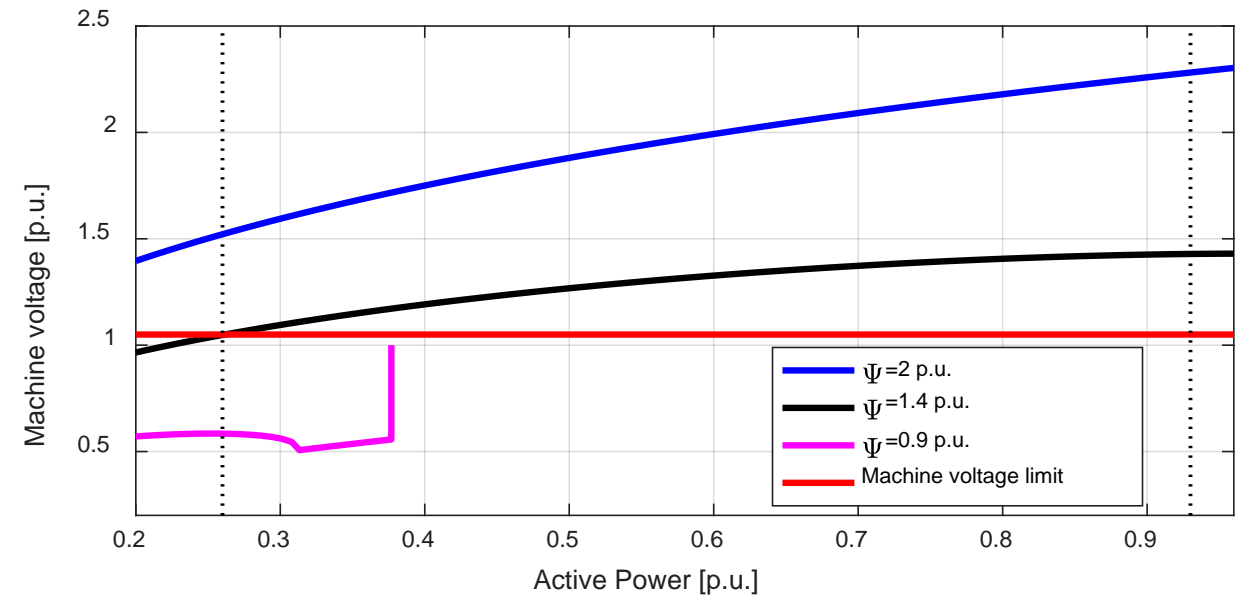

Fig. 7: Active power versus PMSG terminal voltage: UPF regulation mode.

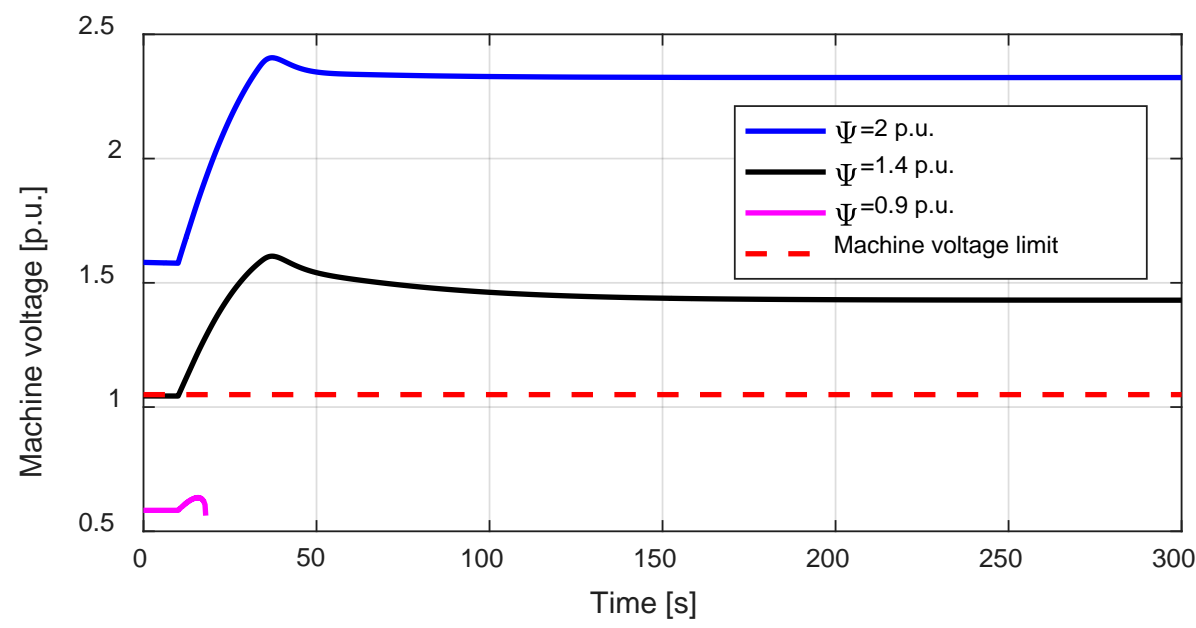

Fig. 8: Results of the time-domain simulation: PMSG terminal voltage response in the UPF regulation mode.

The validation of the results appearing in Fig. 7 is done as before setting up a time-domain simulation that starts from an equilibrium point characterized by an active power equal to $0.25 \mathrm{pu}$. perturbed by a step variation in the wind speed that leads to a final active power equal to $0.95 \mathrm{pu}$.

As can be seen comparing Figs 7 and 8, if the permanent magnet flux is 0.9 pu. it is not possible to reach the final equilibrium point, while if such flux is either 1.4 or $2 \mathrm{pu}$. the final point exists, is the same for both the proposed approach and the time domain simulation but, in both cases, is higher than the maximum allowable voltage (1.05 p.u.)

\subsection{Maximum Torque (MT) strategy}

Finally, the active power/machine current diagram and the active power/machine voltage diagram are plotted in Fig. 9 and Fig. 10 according to the MT control. The two figures compare the strategy described in [13] with the modification provided in Section 3.6. As can be seen, the insertion of the 
second of (13) among the constraints produces a higher current value (which, by the way, remains always lower than 1 p.u.) but forces the voltage to belong to the desired range, thus solving the problem posed in [13].

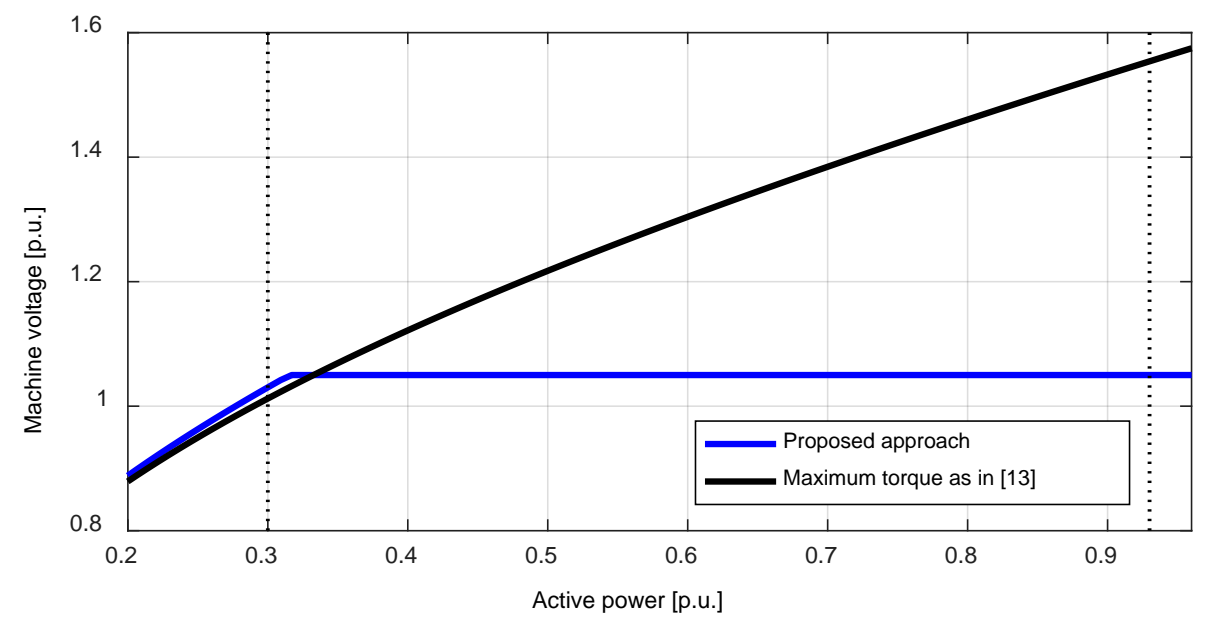

Fig. 9: Active power versus PMSG terminal voltage diagram in the MT regulation mode

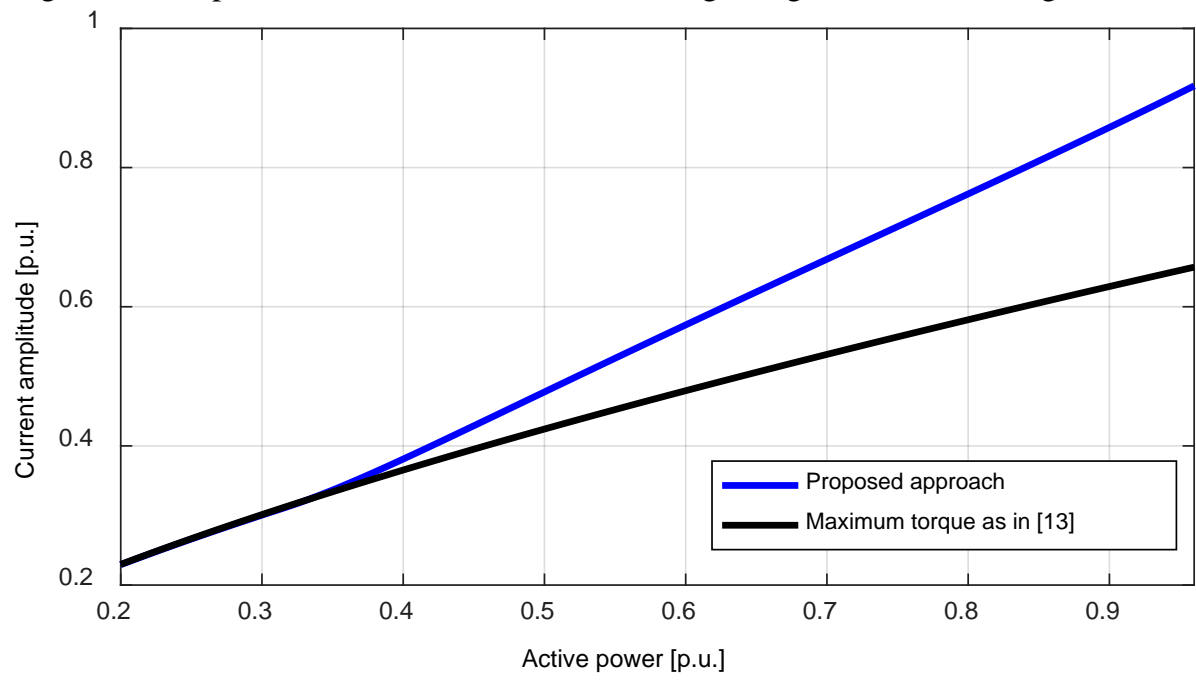

Fig. 10: Active power/PMSG stator current diagram in the MT regulation mode.

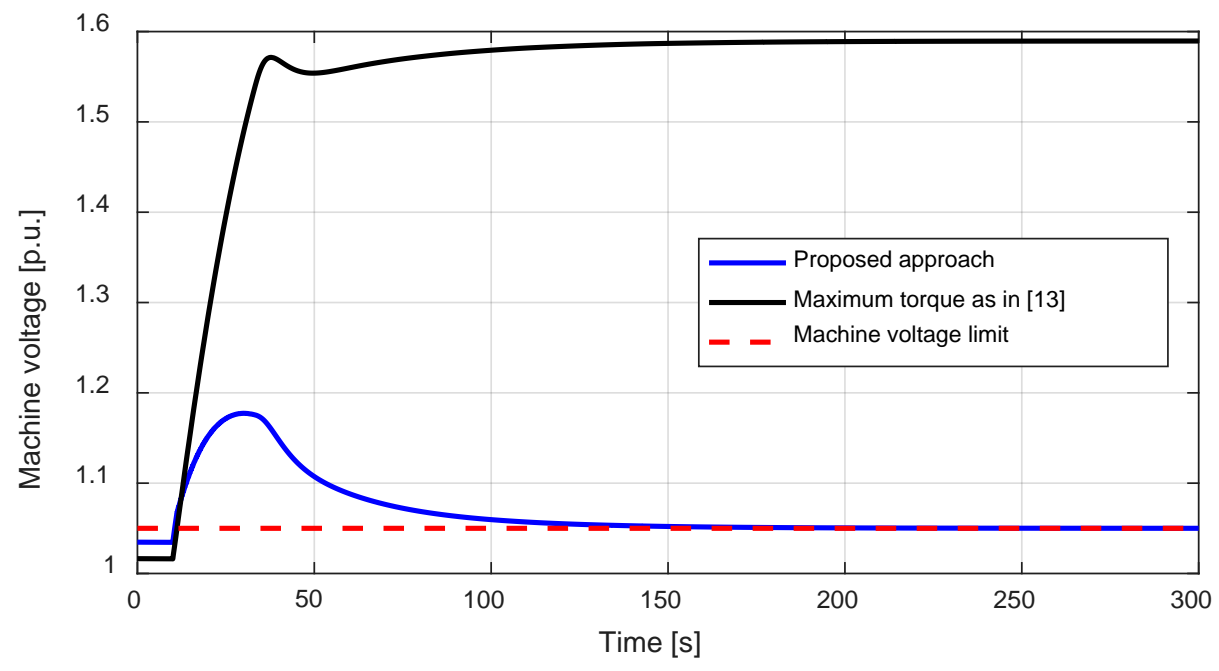

Fig. 11: Time-domain waveform of the machine voltage in the MT regulation mode. 
The time-domain simulation (Fig. 11) confirms the fact that the proposed approach is able to keep, at steady-state, the voltage into the feasibility range, while the strategy described in [13] produces a machine voltage final value slightly smaller than 1.6 p.u..

\section{Conclusions}

The present paper has provided a methodology to assess the feasibility of the steady-state working points of the PMSG based WTG avoiding the running of a set of time-consuming time-domain simulations. The methodology is based on an analytical characterization of the WTG and of the MSC in order to characterize the steady-state of the system in accordance to the MSC control strategy. This methodology allows pointing out possible critical steady-state operational condition using a compact mathematical process based on the main PMSG electrical parameters. In addition, the methodology application would also allow to properly define the machine permanent magnet flux in order to avoid undesired and potentially dangerous working assets for the PMSG or for the MSC. From this point of view, the permanent magnet flux is the most critical parameter on feasible steady-state operational points, as a consequence, the proposed methodology may be attractive for the wind turbine industry because it will allow an appropriate selection of the control strategy based on the permanent magnet characteristics or vice versa a proper design of the magnet characteristics. Results obtained by the methodology implementation and validation against dedicated time-domain simulations highlighted the accuracy of the method and the applicative interest that may arise from an operational point of view.

\section{REFERENCES}

[1] J. Serrano-González and R. Lacal-Arántegui, "Technological evolution of onshore wind turbines—a market-based analysis," Wind Energy, pp. n/a-n/a, 2016.

[2] F. Gonzalez-Longatt, A. A. Bonfiglio, R. Procopio, and B. Verduci, "Evaluation of Inertial Response Controllers for Full-Rated Power Converter Wind Turbine (Type 4)," presented at the IEEE PES General Meeting 2016, Boston, USA, 2016.

[3] S. M. Tripathi, A. N. Tiwari, and D. Singh, "Grid-integrated permanent magnet synchronous generator based wind energy conversion systems: A technology review," Renewable and Sustainable Energy Reviews, vol. 51, pp. 1288-1305, 11// 2015. 
[4] T. R. S. de Freitas, P. J. M. Menegáz, and D. S. L. Simonetti, "Rectifier topologies for permanent magnet synchronous generator on wind energy conversion systems: A review," Renewable and Sustainable Energy Reviews, vol. 54, pp. 1334-1344, 2// 2016.

[5] F. M. Gonzalez-Longatt, P. Wall, and V. Terzija, "A simplified model for dynamic behavior of permanent magnet synchronous generator for direct drive wind turbines," in PowerTech, 2011 IEEE Trondheim, 2011, pp. 1-7.

[6] D. Zhou, F. Blaabjerg, T. Franke, T. M, x00F, nnes, et al., "Comparison of Wind Power Converter Reliability With Low-Speed and Medium-Speed Permanent-Magnet Synchronous Generators," IEEE Transactions on Industrial Electronics, vol. 62, pp. 6575-6584, 2015.

[7] F. M. Gonzalez-Longatt, "Activation schemes of synthetic inertia controller on full converter wind turbine (type 4)," in Power \& Energy Society General Meeting, 2015 IEEE, 2015, pp. 1-5.

[8] J. Machowski, J. W. Bialek, and J. R. Bumby, Power system dynamics : stability and control, 2nd ed. ed. Oxford: John Wiley, 2008.

[9] P. Kundur, N. J. Balu, and M. G. Lauby, Power system stability and control. New York; London: McGraw-Hill, 1994.

[10] O. Anaya-Lara, Wind energy generation : modelling and control. Oxford: Wiley, 2009.

[11] G. Michalke, A. D. Hansen, and T. Hartkopf, "Control strategy of a variable speed wind turbine with multipole permanent magnet synchronous generator," presented at the 2007 European Wind Energy Conference and Exhibition Milan, Italy, 2007.

[12] S. Grabic, N. Celanovic, and V. A. Katic, "Permanent Magnet Synchronous Generator Cascade for Wind Turbine Application," IEEE Transactions on Power Electronics, vol. 23, pp. 1136-1142, 2008.

[13] S. Li, T. A. Haskew, and L. Xu, "Conventional and novel control designs for direct driven PMSG wind turbines," Electric Power Systems Research, vol. 80, pp. 328-338, 3// 2010.

[14] J. Belhadj and X. Roboam, "Investigation of Different Methods to Control a Small Variable-Speed Wind Turbine With PMSM Drives," Journal of Energy Resources Technology, vol. 129, pp. 200-213, 2006.

[15] H. Nian and Y. Zhou, "Investigation of Open-Winding PMSG System With the Integration of Fully Controlled and Uncontrolled Converter," IEEE Transactions on Industry Applications, vol. 51, pp. 429-439, 2015.

[16] M. F. M. Arani and Y. A. R. I. Mohamed, "Assessment and Enhancement of a Full-Scale PMSGBased Wind Power Generator Performance Under Faults," IEEE Transactions on Energy Conversion, vol. 31, pp. 728-739, 2016.

[17] J. G. Slootweg, S. W. H. d. Haan, H. Polinder, and W. L. Kling, "General model for representing variable speed wind turbines in power system dynamics simulations," IEEE Transactions on Power Systems, vol. 18, pp. 144-151, 2003.

[18] J. G. Slootweg, H. Polinder, and W. L. Kling, "Representing wind turbine electrical generating systems in fundamental frequency simulations," IEEE Transactions on Energy Conversion, vol. 18, pp. 516-524, 2003.

[19] T. Ackermann, Wind power in power systems. Chichester: John Wiley \& Sons, 2005.

[20] F. Gonzalez-Longatt, A. Bonfiglio, R. Procopio, and D. Bogdanov, "Practical limit of synthetic inertia in full converter wind turbine generators: Simulation approach," in 2016 19th International Symposium on Electrical Apparatus and Technologies (SIELA), 2016, pp. 1-5.

[21] H.-W. Kim, S.-S. Kim, and H.-S. Ko, "Modeling and control of PMSG-based variable-speed wind turbine,” Electr. Power Syst. Res., vol. 80, no. 1, pp. 46-52, 2010.

[22] MATLAB, version 8.5.0.197613 (R2015a 64-bit) Natick, Massachusetts: The MathWorks Inc., 2016.

[23] DIgSILENT, "DIgSILENT PowerFactory 2012 SP 3," 14.0.524.2 ed. Gomaringen, Germany, 2016. 